\title{
Reactions of alkaline earth zirconate refractories with titanium alloys
}

Stefan Schafföner

University of Connecticut

\begin{abstract}
$\underline{\text { Abstract }}$
The severe reactivity of titanium alloys with ceramics is a major challenge for their processing. Up to now refractories to melt and cast titanium alloys are selected on the basis of a low Gibbs energy of formation. This kind of selection assumes that an oxide should be stable if its Gibbs energy of formation is lower than the one of any titanium (sub)oxide. The present contribution reviews that these models trying to explain the stability of ceramic materials in contact with titanium alloys are often misleading. By contrast, a dissolution and evaporation based reaction model is more appropriate to describe the reaction of high temperature ceramics with titanium alloys. These explanations were exemplified by research findings of high temperature reactions of titanium alloys with calcium oxide and yttrium oxide. Based on the discussion on calcium and yttrium oxide, the reactions of alkaline earth zirconates such as calcium and barium zirconate with titanium alloys were discussed. The reaction of alkaline earth zirconates is also highly dependent on the titanium alloy composition. It was also demonstrated that not only thermodynamics but also kinetics should be considered to evaluate refractories for titanium processing.
\end{abstract}

\section{Introduction}

A basic problem for the processing of titanium alloys is the reaction with interstitial elements including oxygen, nitrogen and carbon causing their embrittlement [1, 2]. The dissolution of interstitial elements is also one of the main reaction mechanisms of titanium alloys with oxide and non-oxide ceramics [3,4], which significantly affects casting, melting, machining and joining of titanium alloys [3, 5-9]. The severest interaction occurs due to kinetics generally during melting and casting [10], which has been motivating the development of corrosion resistant refractories since the early days of titanium metallurgy. For example, as early as in the 1930s Kroll investigated $\mathrm{CaO}$ as a refractory material for titanium [11], whereas later especially $\mathrm{Y}_{2} \mathrm{O}_{3}$, $\mathrm{ZrO}_{2}, \mathrm{Al}_{2} \mathrm{O}_{3}$ and other rare earth oxides were considered [7]. Many non-oxide ceramics were also investigated, but generally a higher stability was reported for oxide ceramics $[3,7]$.

Highly related to the experimental effort to develop corrosion resistant ceramics are thermodynamic evaluations. Most studies analyzed the stability of refractories by comparing the Gibbs energy of titanium oxide or titanium suboxides with the one of the considered refractory oxides. A number of studies also applied Ellingham-Richardson diagrams comparing the Gibbs 
energy of refractory oxides with titanium (sub-)oxides, and solutions of oxygen in solid titanium. Several of these studies then concluded-depending on the alloy compositions-that oxides such as $\mathrm{CaO}$ and $\mathrm{Y}_{2} \mathrm{O}_{3}$, or even $\mathrm{ZrO}_{2}$ and $\mathrm{Al}_{2} \mathrm{O}_{3}$ should be stable at high temperature $[1,12,13]$. However, experimental results especially contradict calculations that do not take the dissolution of oxygen in titanium into account. For example, in contrast to predictions of Kostov and Friedrich [12], $\mathrm{ZrO}_{2}$ and $\mathrm{Al}_{2} \mathrm{O}_{3}$ refractories react readily with titanium melts $[3,14,15]$. The main reason for this discrepancy is the much lower oxygen potential of dilute solutions of oxygen in titanium [13]. Furthermore, not only oxygen is dissolved to a large extent at high temperatures but also many metallic elements of oxides dissolve in titanium alloys [3].

In the present paper we start by comparing the reaction mechanisms of calcia $(\mathrm{CaO})$ and yttria $\left(\mathrm{Y}_{2} \mathrm{O}_{3}\right)$ with titanium at high temperatures. Based on these considerations we will review recent research on high melting alkaline earth zirconates because they have shown a very promising corrosion behavior, which still needs clarification.

\section{Yttrium oxide}

Yttrium oxide $\left(\mathrm{Y}_{2} \mathrm{O}_{3}\right.$, yttria) is one of the most widely investigated refractory materials for titanium metallurgy due to its high melting point of $2439^{\circ} \mathrm{C}$ and extremely low Gibbs energy of formation. However, yttrium oxide is still not performing totally satisfactory. Depending on the study, an oxygen contamination of 0.06 to $1.6 \mathrm{wt} . \%$ and a contamination of 0 to $1.93 \mathrm{wt} . \%$ was reported when yttria was used as a crucible material [3, 16-22]. Furthermore, several studies also reported pronounced formation of nonmetallic inclusions which were attributed to the erosion of the crucibles by the melt [19-22]. The corrosion of yttria refractories by titanium alloy melts can be explained by relevant phase diagrams. The Ti-Y phase diagram in Fig. 1 shows that the solubility of yttrium in titanium is limited in solid state, but still appreciable. In the liquid state the solubility of titanium and yttrium is almost indefinite. Furthermore, titanium alloy melts have an extremely low oxygen potential and therefore they pose a highly reducing atmosphere for oxide ceramic refractories. 


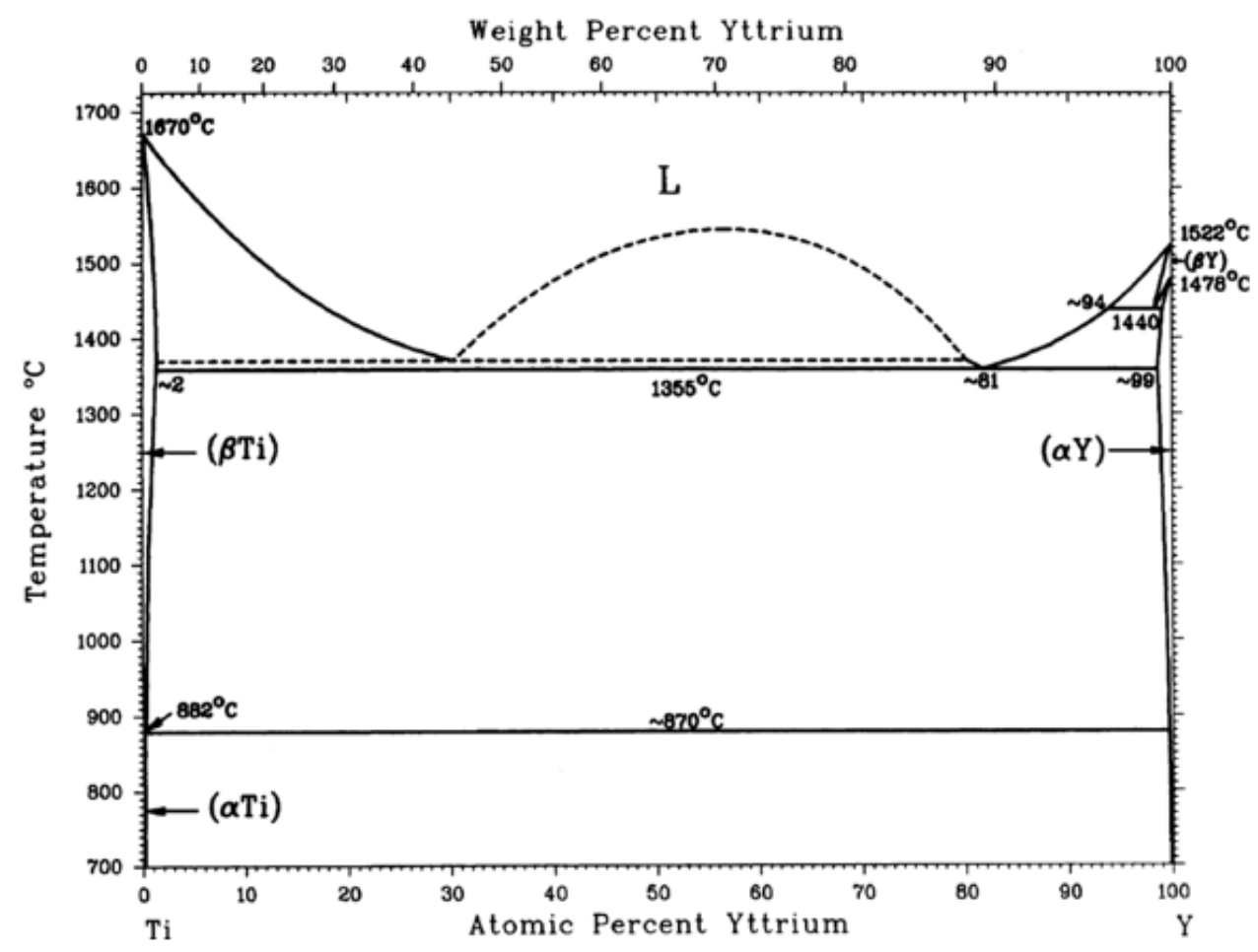

Figure 1: The phase diagram of titanium and yttrium reveals a very high solubility of the liquids and a limited one in solid state [23]. Reprinted by permission from Springer Nature Customer Service Centre GmbH: Springer Nature, Journal of Phase Equilibria and Diffusion (The Ni-Ti-Y (Nickel-Titanium-Yttrium) System, K. P. Gupta), copyright, 2009. 


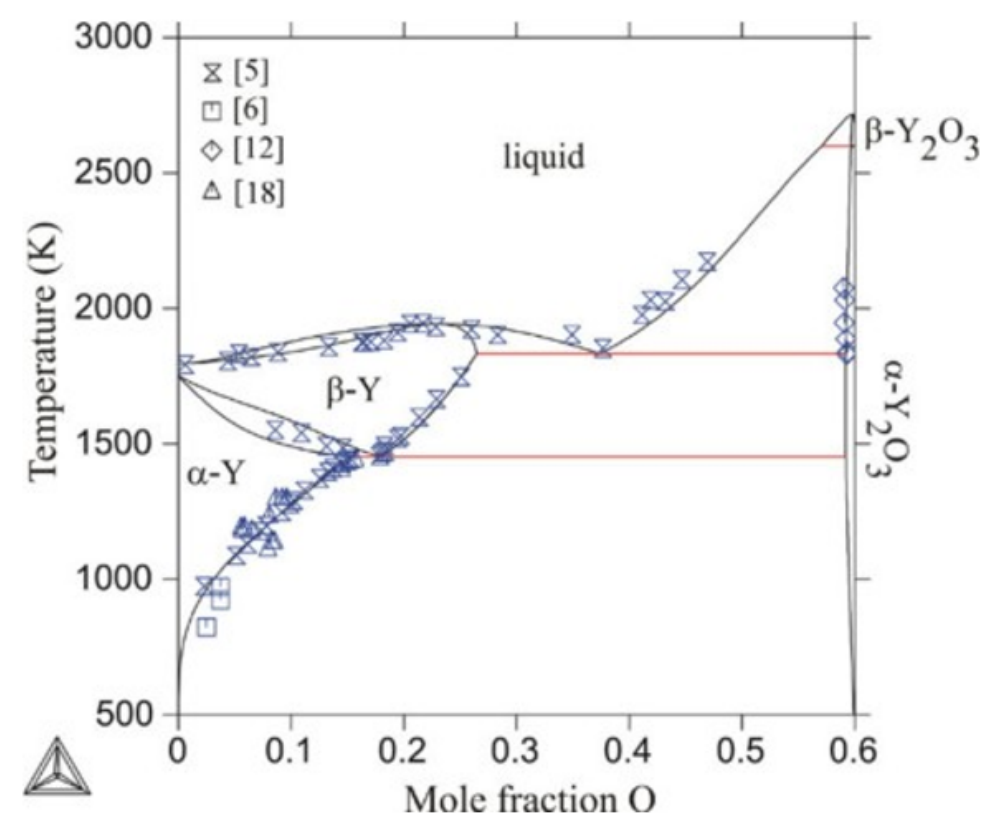

Figure 2: The phase diagram of yttrium and oxygen shows that at very high temperatures yttrium oxide is first reduced to an oxide, which is slightly oxygen deficient. Then this oxygen deficient phase is further reduced to an ionic liquid [24]. The stability diagram of yttrium oxide is shown in Fig. 3. Reprinted from Calphad, 31.4, D. Djurovic, M. Zinkevich, and F. Aldinger, Thermodynamic modeling of the yttrium-oxygen system, pp. 560-566, copyright (2007), with permission from Elsevier. 


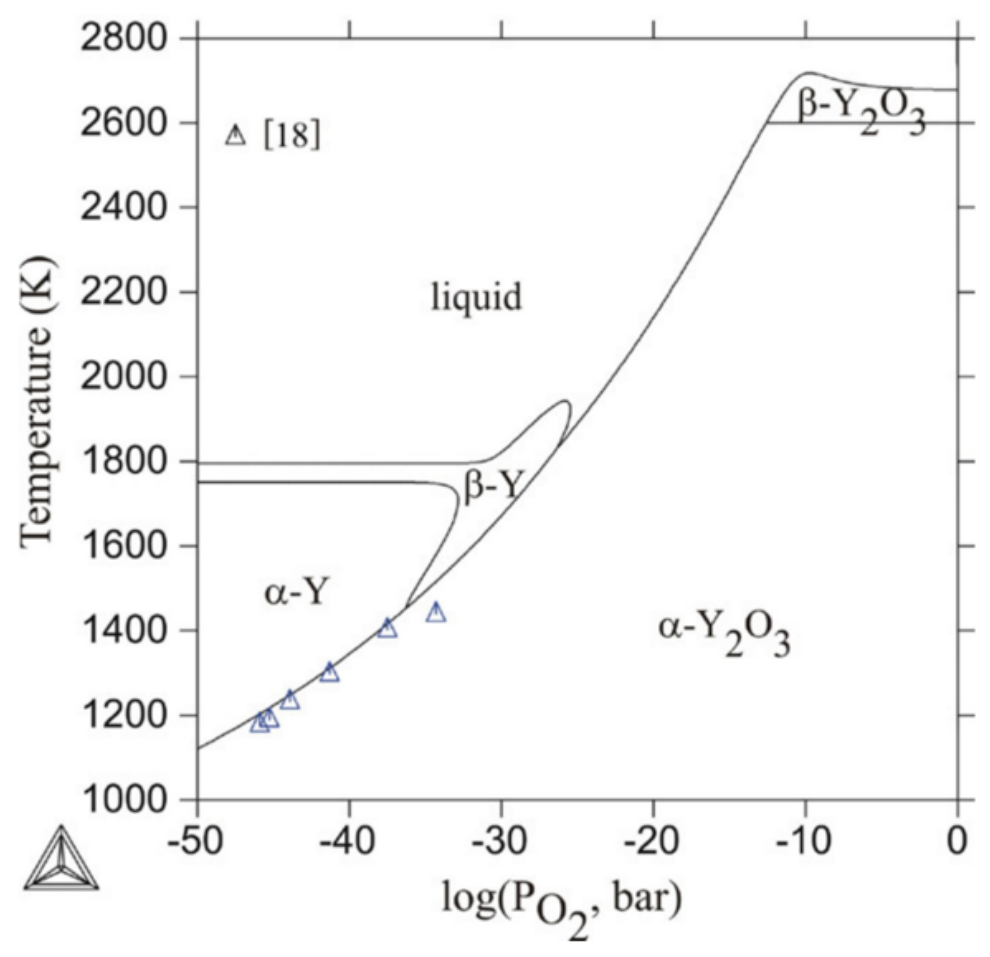

Figure 3: The stability diagram of yttrium oxide demonstrates that at exceedingly low oxygen potentials yttrium oxide is first reduced to an ionic liquid before it is further reduced to oxygen-yttrium solid [24]. Reprinted from Calphad, 31.4, D. Djurovic, M. Zinkevich, and F. Aldinger, Thermodynamic modeling of the yttrium-oxygen system, pp. 560-566, copyright (2007), with permission from Elsevier.

According to the oxygen-yttrium phase diagram in Fig. 2 and the corresponding stability diagram in Fig. 3, at low oxygen potentials and temperatures exceeding about $1800 \mathrm{~K}$, yttrium oxide becomes first oxygen deficient before it is further reduced to an ionic liquid. Considering these phase diagrams, the reaction of titanium melts with yttrium oxide can be readily explained. Since titanium melts present an exceedingly low oxygen potential, the mechanisms of the reduction of yttrium oxides apply. The oxygen released from yttria is then dissolved by the titanium melt. Then follows the formation of an ionic liquid from the oxygen deficient yttrium oxide, whereas both yttrium and oxygen are finally dissolved by the melt. The stability diagram in Fig. 3 also explains the yttrium oxide inclusions in solidified titanium. As explained, titanium dissolves yttrium and oxygen at high temperatures. However, at temperatures below about $1800 \mathrm{~K}, \alpha$ - 
$\mathrm{Y}_{2} \mathrm{O}_{3}$ becomes stable again. Due to the low solubility of yttrium in solid titanium, solid yttrium oxide can form in the solidified titanium. The grain boundaries of the solidified titanium then act as points of nucleation. Thus, it is highly likely that the $\mathrm{Y}_{2} \mathrm{O}_{3}$ particles in solidified titanium are tertiary inclusions instead of eroded particles.

\section{Calcium oxide}

$\mathrm{CaO}$ has also an extremely high melting point of $2899^{\circ} \mathrm{C}$ [25] and an exceedingly low Gibbs energy of formation, whereas calcium has a very low solubility in titanium [26]. However, a major drawback of calcium oxide refractories is the fast reaction below $511^{\circ} \mathrm{C}$ with water to $\mathrm{Ca}(\mathrm{OH})_{2}$ [27]. This reaction then causes the deterioration of the refractories. Another disadvantage of calcium oxide is the high thermal expansion coefficient, which results in a poor thermal shock resistance [29]. To evaluate $\mathrm{CaO}$ as a refractory material for titanium melts, its decomposition reaction has to be considered. Equation (1) shows that calcium oxide decomposes to calcium gas and oxygen.

$$
\mathrm{CaO} \rightarrow \mathrm{Ca}(\mathrm{g})+0.5 \mathrm{O}_{2}(\mathrm{~g})
$$

Due to this decomposition, a strong evaporation of calcium during the melting of titanium alloys was often reported, whereas the oxygen is picked up by the melt [18, 30-32]. For this reason the low oxygen impurities of low-alloyed titanium alloys in the patent description of Degawa [33] seem at least questionable. According to the principle of Le Chatelier the evaporation of calcium then causes a kinetically fast reaction and hence corrosion of calcia refractories. Calcia therefore suffers from a lack of corrosion stability with many low-alloyed titanium melts. In general, however, a stability of calcia crucibles was reported for titanium aluminide melts. The reasons for this stability are a much lower melting temperature of only $1460^{\circ} \mathrm{C}$ and a possible calcium aluminate formation [18].

\section{Alkaline earth zirconates}

As discussed above, the performance of $\mathrm{CaO}$ and $\mathrm{Y}_{2} \mathrm{O}_{3}$ is still not satisfactory resulting from the strong evaporation of calcium and the perceivable solution of yttrium, respectively. Therefore, a refractory material for titanium metallurgy has to circumvent these two reaction mechanisms. Alkaline earth zirconates, i.e. $\mathrm{CaZrO}_{3}, \mathrm{SrZrO}_{3}$ and $\mathrm{BaZrO}_{3}$, have been only relatively recently been considered for titanium metallurgy. They all have extremely high melting points of $2368^{\circ} \mathrm{C}$, $2646^{\circ} \mathrm{C}$ and $2700^{\circ} \mathrm{C}$ [34-36]. Furthermore, their equilibrium vapor pressure is much lower compared to the respective alkaline earth oxides $(\mathrm{Ca}, \mathrm{Sr}, \mathrm{Ba}) \mathrm{O}$ [35]. However, whereas $\mathrm{CaZrO}_{3}$ and $\mathrm{SrZrO}_{3}$ are mainly in equilibrium with calcium and strontium gas, respectively, $\mathrm{BaZrO}_{3}$ is in equilibrium with $\mathrm{BaO}$. Since all three compounds have a very low Gibbs energy of formation, the homogeneity range in the respective $(\mathrm{Ca}, \mathrm{Sr}, \mathrm{Ba}) \mathrm{O}-\mathrm{ZrO}_{2}$ phase diagrams is very narrow. During synthesis from $(\mathrm{Ca}, \mathrm{Sr}, \mathrm{Ba}) \mathrm{O}$ hydroxides and carbonates it has to be ensured that the resulting raw 
materials are free of impurities such as $\mathrm{ZrO}_{2}$ or $(\mathrm{Ca}, \mathrm{Sr}, \mathrm{Ba}) \mathrm{O}[4,37]$.

Refractory raw materials based on alkaline earth zirconates can be generally produced by solidstate synthesis or electro fusion. Electro fusion results in a higher density [38], which is often associated with a higher corrosion resistance, but the fusion process can also cause the evaporation of the alkaline earth component $(\mathrm{CaO}, \mathrm{BaO})$, causing free $\mathrm{c}-\mathrm{ZrO}_{2}[37,39,40]$.

Solid-state synthesis usually allows better control of the chemical composition. In case of $\mathrm{CaZrO}_{3}$, a solid-state processing route for refractory raw materials was recently reported [41], whereas $\mathrm{BaZrO}_{3}$ has the drawback that often $\mathrm{BaO}$ evaporates during solid state synthesis [42]. The phase purity and density of $\mathrm{BaZrO}_{3}$ for refractory applications can be improved by doping, for example with $\mathrm{Y}_{2} \mathrm{O}_{3}, \mathrm{CaO}$ or $\mathrm{TiO}_{2}$ [43].

$\mathrm{CaZrO}_{3}$ was evaluated in recent years in contact with commercially pure titanium (cp-Ti), Ti6Al4V, titanium aluminide (TiAl) and TiFe [44-48]. Especially in contact with the predominant titanium alloy Ti6Al4V $\mathrm{CaZrO}_{3}$ showed a remarkable corrosion resistance when used as investment casting molds. The direct comparison with commercially available molds based on $\mathrm{Y}_{2} \mathrm{O}_{3}$ revealed a much lower hardness increase, an excellent demolding and metallic shiny color [46, 47]. However, as was demonstrated by Schafföner et al. [44], c- $\mathrm{ZrO}_{2}$ impurities cause a stronger corrosion during vacuum induction melting experiments resulting from the dissolution of zirconium and oxygen. $\mathrm{CaO}$ impurities made effective melting impossible due to melt bubbling. Moreover, the reaction with TiAl, was significantly different [45]. The contamination with zirconium was quite high, whereas the oxygen content in the solidified metal was lower than would have been expected from the zirconium contamination. At the crucible interface, a strong calcium aluminate formation was observed. It can be therefore inferred that $\mathrm{CaZrO}_{3}$ was dissolved by the melt and the aluminum from the melt reacted with the oxygen and calcium of the crucible to calcium aluminates. However, the $\mathrm{CaO}-\mathrm{Al}_{2} \mathrm{O}_{3}$ system has a eutectic at $1365^{\circ} \mathrm{C}$ [49]significantly lower than the melting temperature of TiAl of about $1460^{\circ} \mathrm{C}[18]$. This temperature difference explains the quite pronounced corrosion.

The investigations in contact with cp-Ti revealed a very strong reaction, especially by dissolution [50]. Nevertheless, the raw material used in this study was fused $\mathrm{CaZrO}_{3}$, which contained a significant amount of $\mathrm{c}-\mathrm{ZrO}_{2}$ impurities resulting from electro fusion, as explained above. Furthermore, the melting crucible was quite small and the melting temperature control was less than ideal.

Barium zirconate was also extensively evaluated as a refractory material for titanium alloys in recent years. Most studies considered the interaction with TiAl and its derivates, TiNi and $\mathrm{Ti}_{2} \mathrm{Ni}$. The interaction with Ti6Al4V and cp-Ti was, to the best of our knowledge, not investigated in depth. The thermodynamic interaction of barium zirconate with titanium alloys was analyzed with a dissolution model [40]. It was observed that a higher titanium activity significantly increased the corrosion of $\mathrm{BaZrO}_{3}$. The main reason was a strong evaporation of $\mathrm{BaO}$ causing a 
kinetically fast reaction. The corrosion was reduced by additions of $\mathrm{CaO}$ and $\mathrm{Y}_{2} \mathrm{O}_{3}$, whereas the reduced corrosion can be explained by a lower Gibbs energy of formation of the solid oxide solutions. However, $\mathrm{Y}_{2} \mathrm{O}_{3}$ doping lead to poor sintering, which again was circumvent by additions of $\mathrm{TiO}_{2}$, which increased the sintering density [44].

The understanding and processing of refractories for titanium alloy melts has improved in the last years, but several topics remain to be addressed. In the future, thermodynamic and kinetic studies should be carried out in solid and liquid state to further elucidate the equilibria and dissolution reactions of the refractory ceramics as function of the titanium alloy composition. Furthermore, although corrosion resistance is of foremost importance, similarly important are thermal shock resistance as well as processing techniques and the development of coarse grained raw materials.

\section{Conclusions}

The present study reviewed current research on refractories for titanium alloy processing including melting and casting. The interaction of titanium alloys with refractories must not be considered as a simple redox reactions using Ellingham diagrams. Instead an approach which takes the dissolution of oxygen and the metallic element into titanium, either in liquid or in solid state, has to be taken into account. On the other hand, the kinetics of the interaction of the titanium alloys with the ceramics have to be also considered. Especially a low vapor pressure of the oxides is crucial to ensure slow reaction kinetics. It was analyzed that calcium oxide, which decomposes to oxygen and calcium, shows a fast dissolution with cp-Ti and Ti6Al4V due to the high vapor pressure of calcium. On the other hand, $\mathrm{Y}_{2} \mathrm{O}_{3}$ partially dissolves in titanium alloys, but has a low vapor pressure.

Based on this discussion, recently developed alkaline earth zirconates for titanium alloys were reviewed. They have a very low vapor pressure, which improves their stability for titanium metallurgy tremendously. However, it was also demonstrated that they are not completely inert with titanium alloys and that they generally perform better in contact with titanium alloys with a low titanium activity. Furthermore, the formation of new phases at the interface of titanium melts and refractories has be evaluated for aluminum containing alloys. Finally, corrosion resistance of refractories for titanium alloys has to be analyzed in conjunction with other crucial properties including thermal shock and creep resistance.

\section{Acknowledgment}

The author would like to thank the German Research Foundation (DFG) for supporting this research under grant number SCHA 1960/1-1 as well as the Institute of Material Science (IMS) and the School of Engineering of the University of Connecticut for faculty startup funds.

\section{$\underline{\text { References }}$}

[1] Y. Zhang, Z. Z. Fang, P. Sun, S. Zheng, Y. Xia, and M. Free. JOM 69.10 (2017), 1861-1868. 
[2] W. L. Finlay and J. A. Snyder. Transactions AIME 188 (1950), 277-286.

[3] R. L. Saha, T. Nandy, R. Misra, and K. Jacob. Metallurgical Transactions B 21.3 (1990), $559-566$.

[4] S. Schafföner, C. G. Aneziris, H. Berek, B. Rotmann, and B. Friedrich. Journal of the European Ceramic Society 35.1 (2015), 259-266.

[5] Oliver Hatt, H. Larsson, F. Giuliani, P. Crawforth, B. Wynne, and M. Jackson. Procedia CIRP 45 (2016). 3rd CIRP Conference on Surface Integrity, 219-222.

[6] S. Simões. Metals 8.11 (2018). paper 876.

[7] C. Frueh, D. R. Porier, M. C. Maguire, and R. A. Harding. International Journal of Cast Metals Research 9 (1996), 233-239.

[8] Q. W. Qiu, Y. Wang, Z. Yang, and D. Wang. Journal of the European Ceramic Society 36.8 (2016), 2067-2074.

[9] A. Mitchell and D.W. Tripp. SAMPE Quarterly 20.2 (1989), 38-41.

[10] C. Frueh, D. R. Poirier, and M.C. Maguire. Metallurgical and Materials Transactions B 28.5 (1997), 919- 926.

[11] W. Kroll. Metallwirtschaft 18.4 (1939), 77-80.

[12] A. Kostov and B. Friedrich. Computational Materials Science 38.2 (2006), 374-385.

[13] K.T. Jacob and S. Gupta. JOM 61.5 (2009), 56-59.

[14] U. E. Klotz and T. Heiss. International Journal of Cast Metals Research 27.6 (2014), 341348.

[15] B. C. Weber, W. M. Thompson, H. O. Bielstein, and M. A. Schwartz. Journal of the American Ceramic Society 40.11 (1957), 363-373.

[16] R. L. Helferich and C. A. Zanis. Tech. Rep. National Technical Information Service, 1973.

[17] C. E. Holcombe and T. R. Serandos. Metallurgical Transactions B 14.3 (1983), 497-499.

[18] B. Friedrich, J. Morscheiser, and C. Lochbichler. In: 51st International Colloqium on Refractories. 2008, 229-232.

[19] T. Tetsui, K. Kobayashi, T. Mori, T. Kishimoto, and H. Harada. Materials Transactions 51.9 (2010), 1656.

[20] F. Gomes, H. Puga, J. Barbosa, and C. S. Ribeiro. Journal of Materials Science 46.14 (2011), 4922-4936.

[21] R. J. Cui, M. Gao, H. Zhang, and S. K. Gong. Journal of Materials Processing Technology 210.9 (2010), 1190-1196.

[22] M. Gao, R. J. Cui, L. M. Ma, H. R. Zhang, X. X. Tang, and H. Zhang. Journal of Materials Processing Technology 211.12 (2011), 2004-2011.

[23] K. P. Gupta. Journal of Phase Equilibria and Diffusion 30.4 (2009), 402-405.

[24] D. Djurovic, M. Zinkevich, and F. Aldinger. Calphad 31.4 (2007), 560-566.

[25] M. Hillert and X.Z. Wang. Calphad 13.3 (1989), 267-271.

[26] F. Tsukihashi, T. Hatta, and E. Tawara. Metallurgical and Materials Transactions B 27 (6 1996), 967-972. 
[27] Z. Li, S. W. Zhang, and W. E. Lee. International Materials Reviews 53.1 (2008), 1-20.

[28] T.H. Nielsen and M.H. Leipold. Journal of the American Ceramic Society 46.8 (1963), 381-387.

[29] D. P. H. Hasselman. Journal of the American Ceramic Society 52.11 (1969), 600-604.

[30] W. Kroll. Transactions of the Electrochemical Society 78.1 (1940), 35-47.

[31] K. Sakamoto, K. Yoshikawa, T. Kusamichi, and T. Onoye. ISIJ international 32.5 (1992), 616-624.

[32] S. K. Kim, T. K. Kim, T. W. Hong, and Y. J. Kim. In: Lightweight alloys for aerospace applications. 2001, 251-260.

[33] T. Degawa, G. Okuyama, A. Hashimoto, S. Uchida, K. Fujiwara, M. Ebata, T. Satou, and T. Ototani. US Patent 4,710,481. Dec. 1987.

[34] Y. Du, Z. P. Jin, and P. Y. Huang. Journal of the American Ceramic Society 75.11 (1992), 3040-3048.

[35] N. S Jacobson. Tech. Rep. DTIC Document, 1989.

[36] D. Dierickx, L Houben, J. Lapin, F. Delannay, and O. Van der Biest. Journal of Materials Science Letters 15.18 (1996), 1573-1576.

[37] S. Schafföner, J. Fruhstorfer, C. Faßauer, L. Freitag, C. Jahn, and C. G. Aneziris. Journal of the European Ceramic Society 37.1 (2017), 305-313.

[38] S. Schafföner, C. Dietze, S. Möhmel, J. Fruhstorfer, and C. G. Aneziris. Ceramics International 43.5 (2017), 4252-4262.

[39] S. Schafföner, C. G. Aneziris, H. Berek, J. Hubálková, and A. Priese. Journal of the European Ceramic Society 33.15-16 (2013), 3411-3418.

[40] G. Y. Chen, B. B. Lan, F. H. Xiong, P. Y. Gao, H. Zhang, X. G. Lu, and C. H. Li. Vacuum 159 (2019), 293-298.

[41] C. Jahn, S. Schafföner, C. Ode, H. Jansen, and C. G. Aneziris. Ceramics International 44.10 (2018), 11274-11281.

[42] Y. Oyama, A. Kojima, X. Li, R. B. Cervera, K. Tanaka, and S. Yamaguchi. Solid State Ionics 197.1 (2011), 1-12.

[43] J. Kang, G. Y. Chen, B. B Lan, R. Zhang, W. Ali, X. G. Lu, and C. H. Li. International Journal of Applied Ceramic Technology 16.3 (2019), 1088-1097.

[44] S. Schafföner, C. G. Aneziris, H. Berek, J. Hubálková, B. Rotmann, and B. Friedrich. Journal of the European Ceramic Society 35.1 (2015), 259-266.

[45] S. Schafföner, C. G. Aneziris, H. Berek, J. Hubálková, B. Rotmann, and B. Friedrich. Journal of the European Ceramic Society 35.3 (2015), 1097-1106.

[46] L. Freitag, S. Schafföner, N. Lippert, C. Faßauer, C. G. Aneziris, C. Legner, U. E. Klotz. Ceramics International 43.9 (2017), 6807-6814.

[47] U. E. Klotz, C. Legner, F. Bulling, L. Freitag, C. Faßauer, S. Schafföner, and C. G. Aneziris. The International Journal of Advanced Manufacturing Technology 103.1 (2019), 343353. 
[48] B. Yang, K. Zhu, X. Lu, Z. Li, Z. Wu, G. Wu, and C. H. Li. The Chinese Journal of Process Engineering 12.5 (2012), 849-856.

[49] B. Hallstedt. Journal of the American Ceramic Society 73.1 (1990), 15-23.

[50] S. Schafföner, B. Rotmann, H. Berek, B. Friedrich, and C. G. Aneziris. Proceedings of the Unified International Technical Conference on Refractories (UNITECR 2013). John Wiley \& Sons, Inc., 2014, 1303-1308. 